\title{
STRUCTURAL AND OPERATIONAL COMPLEXITY OF MANUAL ASSEMBLY SYSTEMS
}

\author{
Atiya Al-Zuheri \\ School of Engineering, University of South Australia, Mawson Lakes, South Australia and \\ Ministry of Science and Technology, Al-Jadriya, 10070 Baghdad, Iraq
}

Received 2013-10-14, Revised 2013-11-05; Accepted 2013-11-26

\begin{abstract}
Increased complexity is one of the biggest challenges in assembly industry today. Designing and implementing manual assembly systems require identifying operational and structural complexity sources inherent with these systems. Lack of this fact causes inaccuracy in the results from the system application. This study details sources of both types of complexity in manual assembly systems. Also, the paper will present the modeling techniques to address these complexities in the design approach of these systems.
\end{abstract}

Keywords: Complexity, Manual Assembly Systems

\section{INTRODUCTION}

Every product that consists of two or more components must be assembled. As the number of components increases there are more alternative ways to execute the assembly operations (Pierreval et al., 2003). An assembly process can be defined as follows: "a group of compounds and/or the parts which are assembled with each other to form a main subdivision for the final product" (Mosier and Janaro, 1990). The assembly process can possibly be for complex endproducts or for compounds or sub-assemblies from that product (Battini et al., 2007).

An assembly line as "dedicated type manufacturing" is a set of sequential workstations in each of which a specific set of tasks are performed on the work pieces. Such workstations are usually connected by a continuous transportation system (Siebers et al., 2004).

\subsection{The Significance of Manual Assembly Systems}

A significant proportion of manufacturing processes and costs are dedicated to the process of product assembly. In fact, approximately $40 \%$ of the total cost of product manufacturing is in the assembly stage (Ritchie et al., 1999). This cost will increase when the process is performed manually. The percentage of labor cost required for completing the assembly operations ranges from 30 to 50\% (De Lit et al., 2003). Also 15$70 \%$ of the total manufacturing time of produced products is dedicated to the assembly process (Lotter and Wiendahl, 2009). Therefore, manufacturing companies are facing making the best use of the pertinent available technology and resources dedicated to assembly process by changing the manual work to automation and robotic cells (Heilala and Voho, 2001).

Despite this trend towards increasing and implementing automated production systems, there is still a significant and justifiable need for manual assembly. Nowadays with rapidly changing consumer needs, desires and tastes, assembly enterprises have discovered that manual assembly systems are still a necessity to enable them to respond quickly and economically to such circumstances. It is due to high capital costs and the limitations of automatic systems to provide adequate flexibility to produce customized products under these circumstances. As a consequence, the manual assembly systems became more widely adopted, associated with expanding worker's tasks and responsibilities as an economical and efficient way for responding to these circumstances (Helander and Burri, 1995). 
The human body despite its capability limitations is still more flexible than machines and the human mind possesses creative and intuitive functions above that of robotic devices (Hunter, 2002). Shalin et al. (1996) attributed the persistence of manufacturers of assembled products on adopting the manual systems due to the following reasons:

- The automated systems require time and specialized skills owing to the need of programming for machines, robotics

- The cooperativeness and willingness of the manual assembly line workers to accept and support the necessary changing processes which occur as a result to changes in products and market situations make the system adaption quick in responding to these changes. This impetus from the workers plays a vital role in increasing flexibility and agility of the assembly system

Manual operations are used in the assembly of complex work elements as well as when production demand is unstable or where the use of specialized machines and equipment is unjustifiably expensive. Thus, caution must be exercised in the design of a manual assembly line, with respect to the volume flexibility with uncertain production demand. To achieve this situation requires adjusting the number of workers or the system configuration according to the changes in production demand. Hence, a manual assembly line is more flexible than automated machine assembly systems in adapting to the changes in production demand (Yoshimura et al., 2006). Figure 1 illustrates the performance of assembly system types: manual assembly, hybrid assembly and automated assembly. Clearly increasing the level of automation in the system leads to productivity increases as well as sharply decreases in the flexibility and control of the diversity of variants.

Based on that, manual assembly systems have the ability to proactively meet emergent and long-term fluctuations. Consequently, in dynamic environment characterized by uncertainty active participation of the workers is considered crucial. The output rate of the worker is dependent on a number of factors, such as the ergonomic design of the workstation and surroundings, e.g., room, light. Moreover, the layout of the workspace plays a significant role. The assembly work should be conducted within the operator's field of vision without them having to move their head and at a height lower than the heart.

\subsection{The Nature of Manual Assembly Work}

In most industrial companies, manual assembly work is characterized by highly repetitive, shortcycled, monotonous, has little variation and low personal control. Moreover, it is associated with low job satisfaction, high absenteeism and excessive mental and physical stress (Melin et al., 1999). Furthermore, the workers of the system have little freedom in selecting their work content. They are almost never called on to make decisions and almost never have an opportunity to plan their own activities (Bullinger et al., 1997). These unsatisfactory conditions could be problematic for the scarce production resource in a manual assembly system, in short, was the worker (Andersson and Olsson, 1998).

Manual work in industrial assembly tasks include lifting, carrying, pushing, pulling of materials and quality control. Sometimes such work is associated with heavy loads and high frequency. In general, this work involves postures that promote fatigue and discomfort like sustained static neck flexion, shoulder flexion, forearm muscle exertion, extreme wrist postures and prolonged standing (Lutz et al., 2001). Assembly work is associated with the exposure mentioned above, often including the use of nonpowered and/or power hand tools. In addition to that, it may have long cycle and excessive walking time including load carrying (Melin et al., 1999).

As was clearly pointed out above, manual assembly system is a whole of linked components which interact each other. Hence, there is a "complexity" in the system refers to the number of connections or influences between the different components of the system (Prigogine, 1981). Next section sheds light on the complexity of manual assembly systems.

\subsection{Overview of the Complexity in Manual Assembly Systems}

As defined by Simon (1962), complexity of the system, means the system has a large number of components and the relationships between these components are not "simple". Herein, simple has been interpreted by Simon (1962) as "single, small" or it means "having or composed of only one thing, element, or part” (HMH, 2000). 


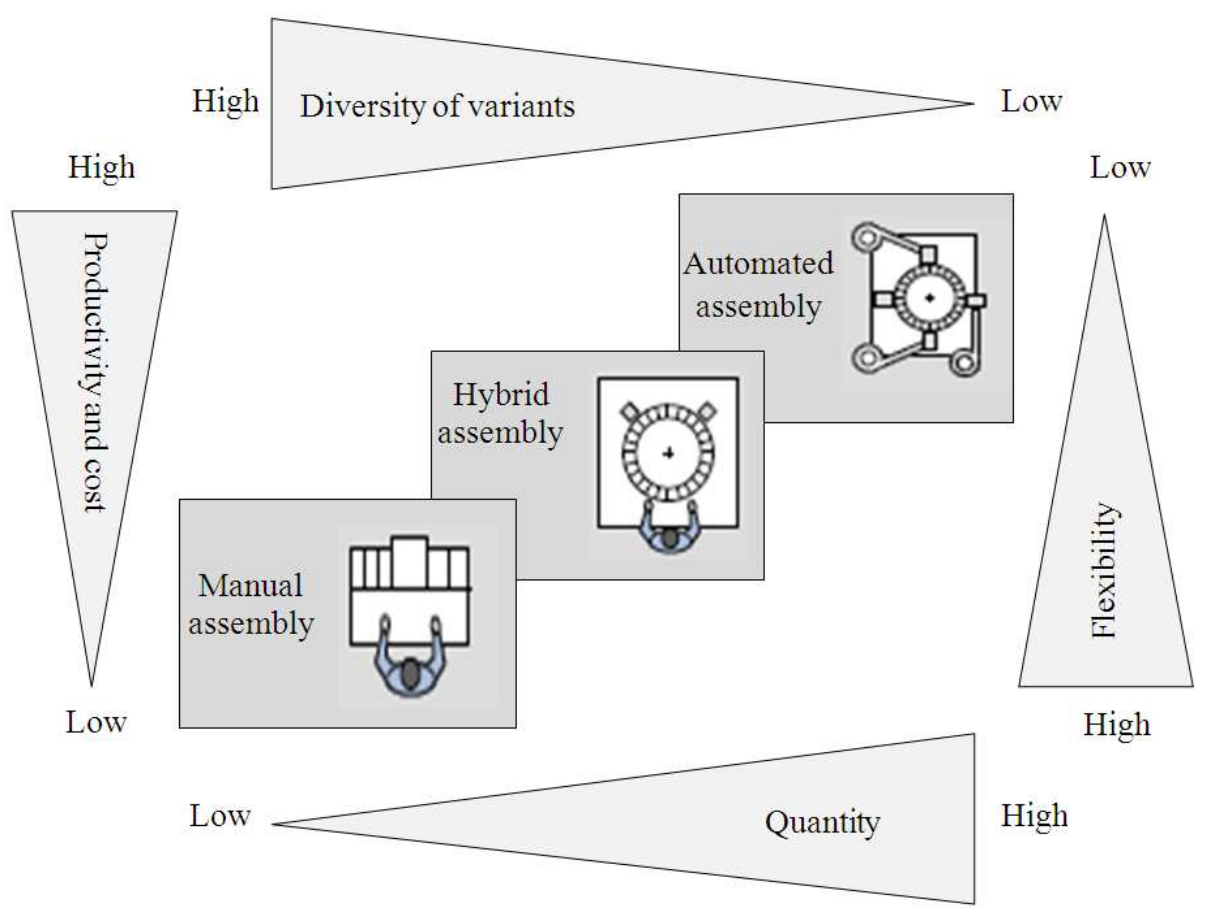

Fig. 1. Assembly system types versus different performance: diversity of variants, productivity and cost, quantity and flexibility (modified from Lotter and Wiendahl, 2009)

Because of the 'socio-technical' nature of manual assembly systems (equipment-technical and humansocial), the assemblage of many system variables in relation to tooling, operators, a material-handling facility and so on and as well the interacting process between these variables clarify the complex overall nature of the system. However, it was recognized by Wang and Chatwin (2005) that the flexible assembly systems (e.g., manual assembly systems) consider one of more complex systems because of the following reasons:

- The extensive interaction between available facilities for production (such as labor, tools, fixtures, information, products and assembly workstations)

- Various uncertainties in production demands (such as production schedules)

- Presence of randomness (such as variability in task completion time)

In fact, all the above-mentioned reasons are mutually compatible with characteristics of complexity (Calinescu, 2002):
- Interdependence: Subsystems are linked each other, so the consequence of an action made on a unit depends of the actions made at the same time on the other units

- Numerousness of the states that units can assume (dimensionality of the system): The number of states that a unit may assume depends of technical or organizational discretionary power they have

- Uncertainty: In complex manufacturing systems, the outside conditions the system must face and the states the system may assume are never completely predictable

- Irreversibility: It means that there is a cost attached to the changing of state, often associated with uncertainty

Generally, there are numerous types of complexity in manufacturing environments including assembly environment and each one flows into the other as shown in Fig. 2 (ElMaraghy and Urbanic, 2003). However the research focuses on two main types of complexity: (1) operational (dynamic) complexity and (2) structural (static) complexity (Gabriel, 2008). 


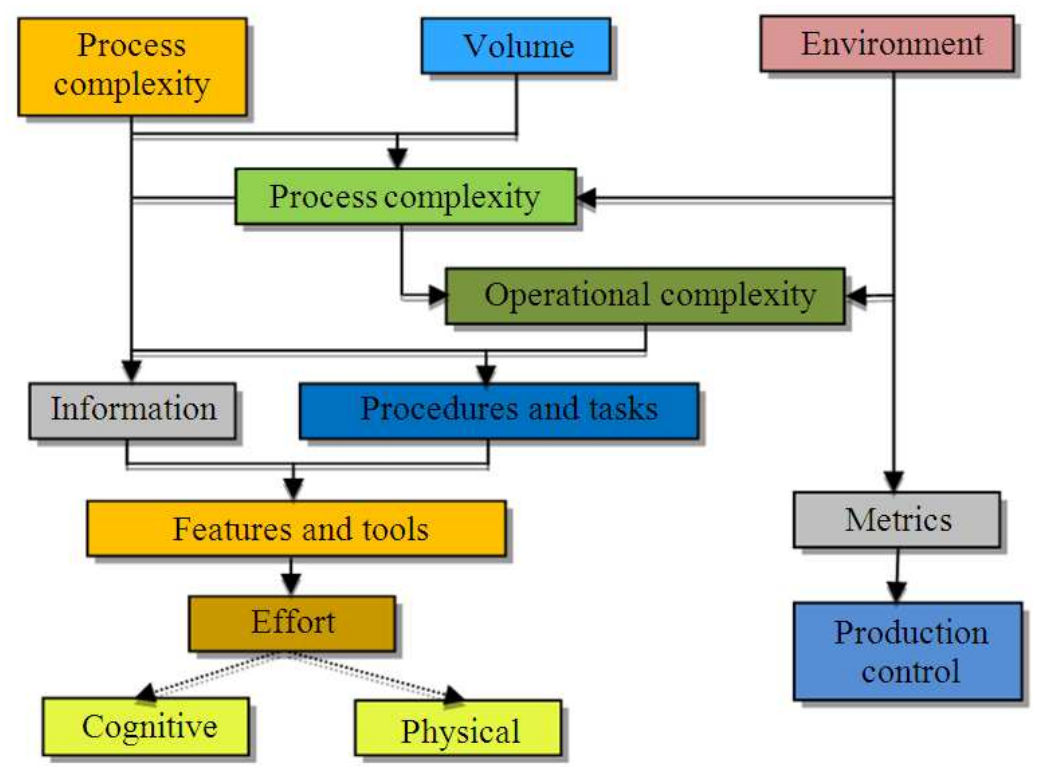

Fig. 2. Manufacturing complexity cascade (ElMaraghy and Urbanic, 2003). As show, complexity affects quality, reliability and performance and production time. However, due to the high complexity in manual assembly tasks it was seen that complex assembly tasks were significantly correlated with the cost of correcting the assembly errors (Falck and Rosenqvist, 2012)

In the following subsections, 2.1 and 2.2 , key elements, or issues of these two types of complexity in manual assembly systems are presented.

\subsection{Operational Complexity}

Operational complexity is a function of the product, process and production logistics (ElMaraghy and Urbanic, 2003). As was previously described in subsection 1.2, the nature of the assembly process at most of the workstations in manual assembly system includes a manual task performed by the worker using simple handpowered equipment such as trimmers, riveting and fastening tools. The process operations at each workstation are relatively small and highly specific to individual components. The workers in manual assembly system have an unaltered, repetitive sequence in which they carry out manual tasks. These tasks consist of the picking up or installing parts, or picking up and using tools and quality checks or inspections at certain production stages. Manual assembly tasks often involve postures that promote fatigue and discomfort. The above described circumstances of work in manual assembly system are well-recognized as the sources for the complexity. These sources are.

Variance in operation time: Operation time variance is systematically varied with increasing amount of manual operation of the task (Matondang and Jambak,
2010). Due to the nature of work in manual assembly system, where assembly activities present a great fraction of manual work and time variability, the variation of operation time becomes more visible. Thereby, this variation influences the computed time per assembled product in the line (ElMaraghy and Manns, 2007).

Variance in skill levels of the workers whom perform the tasks: The other source of variability in task completion times is the worker performing the task (Doerr and Arreola-Risa, 2000). Thus, assuming the skill level of workers is a probability variable is essential in constructing the model of manual assembly system. This can be feasible because the assembly content in the line normally needs the use of simple hand tools, not expensive equipments.

Fatigue effects on work performance: It is well known that worker's performance capacities such as strength, speed, reaction time, coordination, decision making, or balance decreases with hours of shift time (Macdonald and Bendak, 2000).

\subsection{Structural Complexity}

According to Frizelle and Woodcock (1995), structural complexity is related to the probability of resources being in a certain place. In manual assembly systems, there are the different variables that influence the fundamental structure design of the system. Structural 
variables refer to size, shape and topology of the system (Kim and Kwak, 2002). It is necessary to analyse the structure in terms of the relationships between the components of the system. Attention needs to be given to accomplish more flexibility in the system structure and the workforce and the selected operating approach relationship. The "fit" between structure, operating approach and capabilities of labor will depend upon structure variables of the system where several variables affect the structure. The structural decision variables that can affect operation approach and consequently can be considered as sources for complexity: the distance between one workstation and another, system layout design, the number of workstations on the line and roughness of surface floor.

The above described complexities and as well as a specific application and other design considerations in manual assembly systems, the number of performance measures to be optimized simultaneously may vary. Hence, optimization design process for manual assembly systems becomes more complex.

Next, in section 3 , to be able to deal with the high level of complexity inherent in detailed manual assembly systems characteristics, summary the techniques that should use towards modeling complexities in developing an integrated approach to handling the design optimization for manual assembly systems.

\subsection{Techniques for Modeling Complexity of Manual Assembly Systems}

Mathematical and conceptual models of production are relatively complex, even in the case of rigid production systems. In the case of systems with a worker is a key issue in application (e.g., manual assembly systems) models quickly become far more complex (Ahn et al., 1999). Mathematical models are considered from earlier versions of operational research techniques that have been used to model manual assembly system design problems. Extensively research has been used the mathematical models to solve the mentioned design problems. Samples from that research are represented by studies of Dashchenko and Loladze (1991); Hillier and So (1996); Martin (1994) and Solot and Vliet (1994).

Due to the sources of complexities in manufacturing systems that stated earlier, most of these systems are stochastic rather than deterministic (Wang and Chatwin, 2005). Among specialists, it is widely accepted that using mathematical modeling techniques are not sufficient to describe a system with complexity (Wang and Chatwin,
2005; Wang et al., 2009). This is because mathematical models do not consider the stochastic nature of the system, based on many simplifying assumptions and provide a limited number of system performance measures (Hsieh, 2002). Consequently, the accuracy often becomes a major problem for system optimization using mathematical models (Wang and Chatwin, 2005; Wang et al., 2009). Simulation modeling has emerged as a powerful tool for optimizing of complex manufacturing systems that are characterized by stochastic operating environments (Bulgak et al., 1999; Jayaram et al., 2007; Siebers et al., 2004). Currently, simulation modeling is considered the most commonly used technique behind optimization (Shafer and Smunt, 2004). The components of simulation model try to represent with varying degrees of accuracy the actual operations of the real components of the system.

With simulation, the flow of entities through the system is controlled by logic rules that derive from the operating rules which are associated with underlying assumptions. Like other manufacturing systems, the simulation model of the manual assembly systems is used to obtain performance measures values for different combination scenarios of design variables.

There is much published work in simulation modeling-based optimization of manual assembly systems. Examples of this study are shown in several studies (Boer et al., 1991; Chan and Smith, 1993; Jayaram et al., 2007; Kung and Changchit, 1991; Lin and Cochran, 1987).

A simulation modeling technique often requires more effort and costs to obtain solutions than a mathematical one. Also, the accuracy of the model is dependent totally on the quality of the model as well as the skill of the modeler. Lately, sometimes it is hard to interpret the results of simulation.

Because of these limitations, it seems, difficult to adopt the simulation modeling as the sole modeling technique for manual assembly systems. On the other hand, there is no only one technique that can model a system that has such complexities (Al-Ahmari and Ridgway, 1999). Due to existing of complexity in manual assembly systems, both types of models; mathematical and simulation can only be restricted copies of a real system. They are simplifications and abstractions of the real system.

\section{CONCLUSION}

Research on inherent complexity in the manufacturing environments, has become increasingly 
important and attracted the attention of many researchers. The nature of example of such systems which is manual assembly systems is complex system. The complexity in manual assembly systems comes from the variability in performing the tasks in the systems. The major variability includes task variance (variance in operating time); the skills of workers variance (variance in skill levels of the workers whose perform the tasks) and the shift time fatigue variance (variance due to fatigue of work in shift time). Also there is a complexity due to the nature of structural system components and operation approach. This study detailed these sources of complexity. In addition, the techniques to address the complexity presented.

\section{ACKNOWLEDGMENT}

The researcher would like to express their appreciation to anonymous referees for their helpful comments.

\section{REFERENCES}

Ahn, H.S., I. Duenyas and R.Q. Zhang, 1999. Optimal stochastic scheduling of a two-stage tandem queue with parallel servers. Adv. Applied Probability, 31: 1095-1117.

Al-Ahmari, A.M.A. and K. Ridgway, 1999. An integrated modelling method to support manufacturing systems analysis and design. Comput. Indus., 38: 225-238. DOI: 10.1016/S01663615(98)00094-3

Andersson, M. and G. Olsson, 1998. A simulation based decision support approach for operational capacity planning in a customer order driven assembly line. Proceedings of the 30th Conference on Winter Simulation, Washington, D.C., United States, pp: 935-941. DOI: 10.1109/WSC.1998.745793

Battini, D., M. Faccio, E. Ferrari, A. Persona and F. Sgarbossa, 2007. Design configuration for a mixedmodel assembly system in case of low product demand. Int. J. Adv. Manufact. Technol., 34: 188200. DOI: $10.1007 / \mathrm{s} 00170-006-0576-5$

Boer, C.R., J. El-Chaar, E. Imperio and A. Avai, 1991. Criteria for optimum layout design of assembly systems. CIRP Annals Manufact. Technol., 40: 415418. DOI: 10.1016/S0007-8506(07)62019-8

Bulgak, A.A., Y. Tarakc and V. Verter, 1999. Robust design of asynchronous flexible assembly systems. Int. J. Product. Res., 4: 3169-3184. DOI: 10.1080/002075499190220
Bullinger, H., P. Rally and J. Schipfer, 1997. Some aspects of ergonomics in assembly planning. Int. J. Indus. Ergonom., 20: 389-397. DOI: 10.1016/S0169-8141(96)00080-7

Calinescu, A., 2002. Manufacturing complexity: An integrative information-theoretic approach. $\mathrm{PhD}$ Thesis, University of Oxford.

Chan, F.T.S. and A.M. Smith, 1993. Simulation approach to assembly line modification: A case study. J. Manufact. Syst., 12: 239-245. DOI: 10.1016/0278-6125(93)90334-P

Dashchenko, A.I. and T.N. Loladze, 1991. Choice of optimal configurations for flexible (re-adjustable) assembly lines by purposeful search. CIRP Annals Manufact. Technol., 40: 13-16.

De Lit, P., A. Delchambre and J.M. Henrioud, 2003. An integrated approach for product family and assembly system design. IEEE Trans. Robot. Automat., 192: 324-333. DOI: 10.1109/TRA.2003.808853

Doerr, K.H. and A. Arreola-Risa, 2000. A worker-based approach for modeling variability in task completion times. IIE Trans., 32: 625-636. DOI: 10.1023/A:1007659032655

ElMaraghy, H.A. and M. Manns, 2007. Transition of inter arrival time patterns between automated and manual configurations of assembly systems. J. Manufact. Syst., 26: 1-11. DOI: 10.1016/j.jmsy.2008.01.001

ElMaraghy, W.H. and R.J. Urbanic, 2003. Modelling of manufacturing systems complexity. CIRP Annals Manufact. Technol., 52: 363-366. DOI: 10.1016/S0007-8506(07)60602-7

Falck, A.C. and M. Rosenqvist, 2012. Relationship between complexity in manual assembly work, ergonomics and assembly quality.

Frizelle, G. and E. Woodcock, 1995. Measuring complexity as an aid to developing operational strategy. Int. J. Operat. Product. Manage., 15: 26-39. DOI: $10.1108 / 01443579510083640$

Gabriel, T.J., 2008. Measuring the manufacturing complexity created by system design. PhD Thesis, North Georgia College and State University.

Heilala, J. and P. Voho, 2001. Modular reconfigurable flexible final assembly systems. Assembly Automat., 21: 20-30. DOI: 10.1108/01445150110381646

Helander, M.G. and G.J. Burri, 1995. Cost effectiveness of ergonomics and quality improvements in electronics manufacturing in electronics manufacturing. Int. J. Indus. Ergonom., 15: 137-151. DOI: 10.1016/0169-8141(94)00028-2 
Hillier, F.S. and K.C. So, 1996. On the simultaneous optimization of server and work allocations in production line systems with variable processing times. Operat. Res., 44: 435-443. DOI:10.1287/opre.44.3.435

$\mathrm{HMH}$, 2000. The American Heritage Dictionary of the English Language. 4th Edn., Houghton Mifflin Harcourt Publishing Company, Boston, ISBN-10: 0618082301, pp: 2074.

Hsieh, S.J., 2002. Hybrid analytic and simulation models for assembly line design and production planning. Simulat. Modell. Pract. Theory, 10: 87-108. DOI: 10.1016/S1569-190X(02)00063-1

Hunter, S.L., 2002. Ergonomic evaluation of manufacturing system designs. J. Manufact. Syst., 20: 429-444. DOI: 10.1016/S0278-6125(01)80062-5

Jayaram, S., U. Jayaram, Y.J. Kim, C. DeChenne and K.W. Lyons et al., 2007. Industry case studies in the use of immersive virtual assembly. Virtual Reality, 11: 217-228. DOI: 10.1007/s10055-007-0070-x

Kim, I.Y. and B.M. Kwak, 2002. Design space optimization using a numerical design continuation method. Int. J. Numerical Meth. Eng., 53: 19792002. DOI: $10.1002 / \mathrm{nme} .369$

Kung, H.K. and C. Changchit, 1991. A just-in-time simulation model of a PCB assembly line. Comput. Indus. Eng., 20: 17-26. DOI: 10.1016/03608352(91)90036-6

Lin, L. and J.K. Cochran, 1987. Optimization of a complex flow line for printed circuit board fabrication by computer simulation. J. Manufact. Syst., 6: 47-57. DOI: 10.1016/0278-6125(87)90049-5

Lotter, B. and H.P. Wiendahl, 2009. Changeable and Reconfigurable Assembly Systems. In: Changeable and Reconfigurable Manufacturing Systems, ElMaraghy, H.A. (Ed.), Springer, London, ISBN-10: 1848820674, pp: 127-142.

Lutz, T.J., H. Starr, C.A. Smith, A.M. Stewart and M.J. Monroe et al., 2001. The use of mirrors during an assembly task: A study of ergonomics and productivity. Ergonomics, 44: 215-228. DOI: 10.1080/00140130120518

Macdonald, W. and S. Bendak, 2000. Effects of workload level and 8- versus 12-h workday duration on test battery performance. Int. J. Indus. Ergonom., 26: 399-416. DOI: 10.1016/S0169-8141(00)00015-9

Martin, G.E., 1994. Optimal design of production lines. Int. J. Product. Res., 32: 989-1000. DOI: $10.1080 / 00207549408956983$
Matondang, M.Z. and M.I. Jambak, 2010. Soft computing in optimizing assembly lines balancing. J. Comput. Sci., 6: 141-162. DOI: 10.3844/jcssp.2010.141.162

Melin, B., U. Lundberg, J.S. Derlund and M. Granqvist, 1999. Psychological and physiological stress reactions of male and female assembly workers: A comparison between two different forms of work organization. J. Organ. Behav., 20: 47-61. DOI: 10.1002/(SICI)1099-1379(199901)20:1<47::AIDJOB871>3.0.CO;2-F

Mosier, C.T. and R.E. Janaro, 1990. Toward a universal classification and coding system for assemblies. J. Operat. Manage., 9: 44-64. DOI: 10.1016/02726963(90)90145-4

Pierreval, H., C. Caux, J. Paris and F. Viguier, 2003. Evolutionary approaches to the design and organization of manufacturing systems. Comput. Indus. Eng., 44: 339-364. DOI: 10.1016/S03608352(02)00195-X

Prigogine, I., 1981. From Being to Becoming: Time and Complexity in the Physical Sciences. 1st Edn., W H Freeman and Co., ISBN-10: 0716711087, pp: 272.

Ritchie, M., R. Dewar and J. Simmons, 1999. The generation and practical use of plans for manual assembly using immersive virtual reality. Proceedings of the Institution of Mechanical Engineers. Part B, J. Eng. Manufact., 213: 461-474. DOI: 10.1243/0954405991516930

Shafer, S.M. and T.L. Smunt, 2004. Empirical simulation studies in operations management: Context, trends and research opportunities. J. Operat. Manage., 22: 345-354. DOI: 10.1016/j.jom.2004.05.002

Shalin, V.L., G.V. Prabhu and M.G. Helander, 1996. A cognitive perspective on manual assembly. Ergonomics, 39: 108-127. DOI: 10.1080/00140139608964438

Siebers, P.O., T. Baines, S. Mason and J. Ladbrook, 2004. Modelling human variation in assembly line models. Proceedings of the Operational Research, (OR' 04), Dunton, England.

Simon, H.A., 1962. The architecture of complexity. Proc. Am. Philosophical Soc., 106: 467-482.

Solot, P. and M.V. Vliet, 1994. Analytical models for FMS design optimization: A survey. Int. J. Flexible Manufact. Syst., 6: 209-233. DOI: 10.1007/BF01328812

Wang, Q. and C.R. Chatwin, 2005. Key issues and developments in modelling and simulation-based methodologies for manufacturing systems analysis, design and performance evaluation. Int. J. Adv. Manufact. Technol., 25: 1254-1265. DOI: 10.1007/s00170-003-1957-7 
Wang, Q., S. Lassalle, A.R. Mileham and G.W. Owen, 2009. Analysis of a linear walking worker line using a combination of computer simulation and mathematical modeling approaches. J. Manufact. Syst., 28: 64-70. DOI: 10.1016/j.jmsy.2009.12.001
Yoshimura, M., S. Yoshida, Y. KonishI, K. Izui and S. Nishiwaki et al., 2006. A rapid analysis method for production line design. Int. J. Product. Res., 44: 1171-1192. DOI: $10.1080 / 00207540500336355$ 